\title{
Présentation des textes
}

\section{Anne-Yvonne Julien}

\section{(2) OpenEdition}

\section{Journals}

Édition électronique

URL : http://journals.openedition.org/ccs/664

DOI : $10.4000 /$ ccs. 664

ISSN : 2558-782X

\section{Éditeur :}

Presses universitaires de Rennes, Association des lecteurs de Claude Simon

\section{Édition imprimée}

Date de publication : 31 décembre 2010

Pagination : 7-10

ISBN : 9782354120771

ISSN : $1774-9425$

\section{Référence électronique}

Anne-Yvonne Julien, "Présentation des textes », Cahiers Claude Simon [En ligne], 6 | 2010, mis en ligne le 21 septembre 2017, consulté le 24 septembre 2020. URL : http://journals.openedition.org/ccs/664 ; DOI : https://doi.org/10.4000/ccs.664 
Textes 

Le texte « Le Candidat » trouve accueil dans la Revue Arts du 26 novembre 1958. Arts fondé en 1924 par G. Wildenstein, d'abord dévolu aux arts plastiques et musicaux, puis ouvert au champ littéraire ou cinématographique, regroupe des signatures aussi diverses que celles de Audiberti, Giono, Nimier, Boris Vian. Butor s'y exprime, les cinéastes de la Nouvelle vague y trouvent une tribune (Truffaut, Rohmer, Godard, Rivette). La date de publication n'est certes pas indifférente : la revue, qui entend faire découvrir de vrais talents novateurs, a demandé un texte à Claude Simon au moment de l'attribution des prix littéraires ; elle ne peut que regretter haut et fort par la voix de son éditorialiste que Simon n'ait pas été retenu parmi les lauréats. "On avait espéré que le Médicis serait allé à Claude Simon, l'auteur du Vent et de L'Herbe, l'un des meilleurs représentants du Nouveau Roman, avec Michel Butor. Tant pis. En ce qui nous concerne, c'est un texte de Claude Simon que nous publions".

Ce court texte a été présenté aux lecteurs de 1958 avec la mention titulaire de couleur hugolienne "Choses vues par Claude Simon », parce qu'il s'inscrivait en quelque sorte dans le registre de la chronique urbaine et démontrait, s'il en était besoin, la capacité de l'écrivain à user de tous les possibles de l'ironie. Il s'agit, semble-t-il, dans ces pages, du souvenir retranscrit d'une réunion politique dans une ville ayant probablement nom Perpignan, transcription qui s'attache essentiellement à la donnée sonore (effets de claque, éclats de haut-parleur, bribes de discours), comme pour faire ressortir l'allure mécanique et commerciale de la prestation verbale évoquée. Ce ré- 
cit migrera dans la onzième section d'Histoire mais sous une forme éclatée et retravaillée. Si certains paragraphes du texte original réapparaissent presque inchangés dans le roman de 1967 (le quatrième et le dernier, en particulier), l'agencement de ces " choses entendues", plus encore que "vues" en modifient profondément la résonance. L'anonyme initial coïncide maintenant avec Lambert, cette figure ambivalente de copain hâbleur - virtuose de la contrepèterie -, et de politicien opportuniste, récurrente chez Simon, déjà nettement dessinée dans le camarade, discoureur invétéré, du Sacre du Printemps (1954).

L'intonation de dégoût de la voix narrative, ici très sensible, subsiste dans Histoire, mais le tour un peu commentatif du fragment original s'estompe. Seul semble importer cette fois l'entrecroisement des visions du passé et, parfois même, leur affrontement. Lambert, " le candidat ", n'est qu'une des incarnations, parmi d'autres, d'un modernisme mercantile et se fond dans le groupe des importuns d'Histoire, banquier en Sphinx froid, brocanteuse en araignée dévoreuse ou cousin en promoteur rassis. Quant au tempo, il ne cesse de changer : d'un côté les clameurs orchestrées pour celui qui vitupère contre les "Kominformistes », de l'autre, le silence d'une maison vide, mortifère, et pourtant haut refuge de la mémoire et de ses couches disparates, jusques et y compris des moments d'enfance souriants avec ce même Lambert, sur fond de maladie maternelle, en arrière-plan sonore à demi étouffé..

A.-Y. J.

\footnotetext{
Pesanteur d'« homme fait avant l'âge » dont le Je narrateur de la première partie du Sacre du printemps rend compte en ces termes : "Un moment j'ai cru qu'il allait sourire. Comme autrefois au lycée, quand nous étions encore dans les petites classes, après un chahut réussi ou une blague, clignant d'un oeil complice. Mais il s'est déjà repris avant même que son visage ait laissé paraître quoi que ce soit [...], il me regarde avec cet air légèrement supérieur sérieux et fatigué qu'il a commencé à prendre lorsqu'il essayait déjà de nous démontrer avec sa feuille de revendications de potaches l'importance de toutes ces choses et surtout, à travers elles, et je présume pour lui-même encore plus que pour nous, sa propre importance. Le Sacre du printemps, roman, éd. Calmann-Levy, 1985, (1954), p. 84.
} 